\title{
Empirical Study on Physical Exercise Intervention Strategy for Undergraduates' Physical Health
}

\author{
Yali $X u^{1}$, Kaihua $X u^{2}$ \\ ${ }^{1}$ School of Physical Education, Jiangxi University Of Traditional Chinese Medicine, Nanchang, \\ 330004, China \\ ${ }^{2}$ Police Training Management Department, Jiangxi People's Police College, Nanchang, 330103, \\ China
}

Key words: Physical exercise intervention strategy, Undergraduates' physical quality change, Empirical study.

\begin{abstract}
This paper took undergraduates of a university as the objects of study and studied the influence of physical exercise intervention strategy on undergraduates' physical quality change. First of all, this paper analyzed the implementation effect of exercise intervention strategy through total data analysis. The growth of most indexes shows significant difference.
\end{abstract}

\section{Objects of study}

This paper took undergraduates of a university as the objects of study and adopted SAS and paired T test to extract sophomores and juniors in the university. 24 teaching classes were extracted on the basis of individual sports, including badminton, volleyball, martial art and football. The total number of test samples was 670. After invalid data are rejected, the number of effective data samples was 650, including 512 boys and 148 girls. The effective rate is $97.3 \%$.

\section{Research method}

\section{Experimental method}

The experimental period lasted for the whole semester, i.e. 4 months. The number of experimental classes and the control classes is same. Physical education intervention was conducted for experimental classes. The control classes were not intervened and taught according to normal method. Physical education was taught three times per week for experimental classes and control classes, but experimental classes had physical education course twice and extracurricular physical activity once. Then, the scores of students' each index were tested in time before and after the experiment. The same mode was adopted to reduce error as far as possible. In terms of experimental result processing, criss-cross method was applied. The scores of experimental classes and control classes after the experiment were compared laterally, and the results after and before the experiment were compared lengthways. Multiple comparisons and corrections were conducted to study the influence of physical education intervention strategy on undergraduates’ physical health. 


\section{Experimental content and intervention strategy}

Table 1. Experimental content and intervention strategy

\begin{tabular}{|c|l|l|}
\hline $\begin{array}{c}\text { Type of } \\
\text { course }\end{array}$ & \multicolumn{1}{|c|}{ Teaching content } & \multicolumn{1}{|c|}{ Intervention strategy } \\
\hline $\begin{array}{c}\text { Table } \\
\text { tennis } \\
\text { course }\end{array}$ & $\begin{array}{l}\text { Warm-up and physical quality exercise; } \\
\text { explanation, demonstration and practice of table } \\
\text { tennis skills and tactics; table tennis games; } \\
\text { teaching introspection after each lesson is over }\end{array}$ & $\begin{array}{l}\text { Preview before class, class explanation, teacher's } \\
\text { demonstration, students' personal operation, } \\
\text { consultation of teacher in operation process and } \\
\text { teacher's disambiguation. }\end{array}$ \\
\hline $\begin{array}{c}\text { Tennis } \\
\text { course }\end{array}$ & $\begin{array}{l}\text { Popularize physical quality measurement method } \\
\text { and function; explain scientific approach of } \\
\text { physical exercise and basic theoretical knowledge } \\
\text { of tennis course; the teacher sets an example to } \\
\text { introduce basic technical theory and rules of tennis }\end{array}$ & $\begin{array}{l}\text { Change teaching mode to group study, teach students } \\
\text { in accordance of tennis features and let students } \\
\text { experience in practice; the teacher guides in this } \\
\text { process and discusses with students. }\end{array}$ \\
\hline $\begin{array}{c}\text { Aerobics } \\
\text { course }\end{array}$ & $\begin{array}{l}\text { Stress introduction to scientific approach of } \\
\text { physical exercise; students practice in combination } \\
\text { of their physical quality and personal interests }\end{array}$ & $\begin{array}{l}\text { Popularize scientific exercise method through } \\
\text { lectures and reduce accidents; encourage the students } \\
\text { with poor physical quality to participate; according to } \\
\text { students' physical quality, the teacher controls } \\
\text { exercise intensity to reach win-win purpose. }\end{array}$ \\
\hline $\begin{array}{c}\text { Football } \\
\text { course }\end{array}$ & $\begin{array}{l}\text { Basic knowledge of football course, physical } \\
\text { quality measurement method and function; skill } \\
\text { and tactics practice; physical quality practice; } \\
\text { teacher }\end{array}$ & $\begin{array}{l}\text { The teacher guides students' football exercise } \\
\text { through rich football activities to make students } \\
\text { master basic skills of football and improve their } \\
\text { football level. }\end{array}$ \\
\hline
\end{tabular}

\section{Teaching method of physical education intervention strategy}

Physical education intervention is a scientific strategy which is formulated for individual conditions and aims to overall develop physical quality and enhance physical quality. It has very important significance for improving teaching quality of university physical education. Thus, how to better carry out physical education intervention strategy becomes particularly important. Seeing from the whole intervention process, the major point is to enhance students' enthusiasm and independent consciousness in all kinds of activities. Of course, this cannot be separated from teacher's guidance and supervision. There are several teaching means as follows:

a) Physical education idea popularization. In this aspect, more lectures about physical exercise should be organized to motivate students' interest in physical exercise and let those students who do not like exercise and even fear exercise know more about physical exercise and feel the unique charm of physical education.

b) Teaching media innovation. With technological development and multimedia application, traditional chalk and blackboard no longer meet students' requirement for visual impression.

c) Situation creation. In the specific teaching, the teacher should bring students into a specific situation and makes students develop themselves in it so as to arouse sympathy and motivate students' learning interest. Then, the teacher gives detailed explanation to effectively enhance students' understanding.

d) Cooperative learning. In teaching, some interesting or developmental games can be carried out in team form, which can not just reach the purpose of enhancing physical quality, but also cultivate their teamwork spirit. Meanwhile, the educational idea changes to student-oriented teaching from teacher-oriented teaching,

e) Timely feedback. A feedback form (face-to-face feedback or innovative feedback form) should be established between students and teachers. For example, electronic health record of each student can be established in university file system, and updated in time. Then, scientific method may be applied for evaluation, and the evaluation result is sent to each student so that students can enhance their exercise awareness. 


\section{Results on influence of physical exercise intervention strategy on total changes of undergraduates' physical quality}

The general teaching effect of physical exercise intervention strategy can be known from the changes of each index before and after the implementation of strategy.

Table 2. Boys’ physical quality changes

\begin{tabular}{|c|c|c|c|c|}
\hline Index & Before experiment & After experiment & Mean difference & $\mathrm{p}$ \\
\hline Height & $173.2 \pm 5.9$ & $173.5 \pm 6.0$ & -0.3 & $<0.01$ \\
\hline Weight & $63.2 \pm 10.1$ & $63.7 \pm 9.8$ & -0.5 & $<0.05$ \\
\hline Step test & $58.9 \pm 11.8$ & $60.5 \pm 13.3$ & -1.6 & $>0.05$ \\
\hline Vital capacity & $4206.3 \pm 57.9$ & $4302.7 \pm 615.9$ & -96.4 & $<0.01$ \\
\hline Standing long jump & $225.6 \pm 19.5$ & $235.7 \pm 19.8$ & -10.1 & $<0.01$ \\
\hline Gripping strength & $38.3 \pm 9.0$ & $41.5 \pm 9.8$ & -3.2 & $<0.01$ \\
\hline
\end{tabular}

Table 3 Girls’ physical quality changes

\begin{tabular}{|c|c|c|c|c|}
\hline Index & Before experiment & After experiment & Mean difference & $\mathrm{p}$ \\
\hline Height & $161.4 \pm 4.9$ & $161.4 \pm 4.9$ & -0.04 & $>0.05$ \\
\hline Weight & $51.0 \pm 5.8$ & $50.9 \pm 5.4$ & 0.1 & $>0.05$ \\
\hline Step test & $57.0 \pm 11.3$ & $64.5 \pm 13.6$ & -7.5 & $<0.01$ \\
\hline Vital capacity & $2873.4 \pm 518.7$ & $2875.8 \pm 448.5$ & 37.6 & $>0.05$ \\
\hline Standing long jump & $167.7 \pm 15.1$ & $170.3 \pm 14.1$ & -2.5 & $>0.05$ \\
\hline Gripping strength & $34.7 \pm 7.7$ & $37.3 \pm 7.8$ & -2.6 & $<0.01$ \\
\hline
\end{tabular}

It can be seen form Table 2 and Table 3 that, the growth of boys' weight is very significant after physical exercise intervention teaching was implemented in the university $(p<0.05)$, but height standard weight value is controlled within the normal weight scope. The improvement of girls' sit-up shows very significant difference $(\mathrm{p}<0.01)$. Girls' height standard weight value is in the low weight scope. The data change of boys' step test $(\mathrm{p}>0.05)$ is greatly smaller than the change of girls' step test $(p<0.01)$. The growth of boys' other indexes presents very significant difference $(p<0.01)$, while girls' other indexes have no significant divergence ( $p>0.05$ ). Based on the above data, firstly, gender difference will lead to the difference of physical development. Girls develop early, and boys develop late. However, with the increase in the age, boys can further develop, while girls' growth is gradually caught in dead state. Secondly, human physical quality can be changed through postnatal human factor. As long as there is proper method and persistent spirit, one can succeed certainly. Thirdly, girls' physical quality fails to improve greatly, and girls' effect is inferior to boys' effect. According to our daily experience, girls' physical quality is inferior to boys' physical quality. Hence, girls' physical exercise intensity is smaller than boys’ physical exercise intensity. In addition, girls are quiet on the whole, and their motions in sports events are not in place, so the effect is not very good. Fourthly, seeing from the test results, physical exercise intervention strategy improves students' physical quality in general, and the implementation difficulty is not large.

\section{Influence of different sport event intervention strategy on undergraduates' single index change}

Regular exercise of different events will lead to different body adaptation which is not only related to individuals, but also closely related to sport events. However, no matter which adaptation it is, athletic ability will improve. Therefore, we researched various indexes of male undergraduates for different events in order to study the influence of different sport events on physical quality. 


\section{Table tennis}

Table 4. Undergraduates' physical quality test data in table tennis event and data analysis

\begin{tabular}{|c|c|c|c|c|}
\hline Index & Before experiment & After experiment & Mean difference & $\mathrm{p}$ \\
\hline Height & $169.2 \pm 5.2$ & $169.5 \pm 5.3$ & -0.4 & $<0.05$ \\
\hline Weight & $65.6 \pm 14.6$ & $64.5 \pm 13.5$ & 1.2 & $>0.05$ \\
\hline Step test & $54.6 \pm 9.5$ & $57.4 \pm 12.8$ & -2.8 & $>0.05$ \\
\hline Vital capacity & $3993.6 \pm 675.8$ & $3900.3 \pm 702.4$ & 93.3 & $>0.05$ \\
\hline Standing long jump & $208.5 \pm 21.4$ & $221.0 \pm 22.2$ & -12.5 & $<0.01$ \\
\hline Gripping strength & $38.9 \pm 10.1$ & $41.1 \pm 10.4$ & -2.2 & $>0.05$ \\
\hline
\end{tabular}

The relationship between table tennis exercise and undergraduates' physical quality is shown in Table 3. 34 boys participated in table tennis test. Among 6 test indexes, height growth shows significant difference $(p<0.05)$. The growth of standing long jump is very significant $(p<0.01)$. There are no significant changes for the other 4 indexes $(p>0.05)$. Table tennis can help people exercise arms and legs. If one persists in playing table tennis, he can exercise the muscle. Meanwhile, people need to run back and forth constantly, so they can exercise their joint and improve their reaction capacity. The improvement of students' height and standing long jump is closely related to these aspects. Besides, the reason why the changes of other indexes are not significant may be that people need to persist in playing table tennis to treat main and collateral channels. Thus, the effect is not significant.

\section{Tennis}

Table 5. Undergraduates’ physical quality test data in tennis event and data analysis

\begin{tabular}{|c|c|c|c|c|}
\hline Index & Before experiment & After experiment & Mean difference & $\mathrm{p}$ \\
\hline Height & $173.4 \pm 5.5$ & $173.9 \pm 5.5$ & -0.5 & $<0.01$ \\
\hline Weight & $64.1 \pm 8.8$ & $65.2 \pm 8.8$ & -1.1 & $<0.05$ \\
\hline Step test & $54.4 \pm 7.9$ & $54.2 \pm 9.7$ & 0.2 & $>0.05$ \\
\hline Vital capacity & $4291.5 \pm 514.1$ & $4304.2 \pm 526.7$ & -12.7 & $>0.05$ \\
\hline Standing long jump & $226.9 \pm 19.6$ & $233.1 \pm 19.3$ & -6.1 & $<0.05$ \\
\hline Gripping strength & $38.9 \pm 8.4$ & $43.6 \pm 8.6$ & -4.6 & $<0.01$ \\
\hline
\end{tabular}

The relationship between tennis exercise and undergraduates' physical quality is shown in Table 5 . 61 boys participated in tennis event. Among various indexes, the changes in step test and vital capacity are small ( $>0.05)$. The growth of weight and standing long jump is significant $(p<0.05)$. The improvement of height and gripping strength shows very significant difference $(p<0.01)$. The research indicates that those participating in tennis sport frequently have good flexibility and coordination, because this event involves many skills, can fully exercise each aspect of body and improve motion capacity of the whole body. In tennis sport, aerobic respiration and anaerobic respiration alternate and play a great role in adjusting each system. This may be the reason why students' four indexes change significantly. Meanwhile, people play tennis in a narrow and small tennis court, so students' sport intensity fails to enhance greatly. Thus, students' step test and vital capacity change little. 


\section{Aerobics}

Table 6. Undergraduates' physical quality test data in aerobics event and data analysis

\begin{tabular}{|c|c|c|c|c|}
\hline Index & Before experiment & After experiment & Mean difference & $\mathrm{p}$ \\
\hline Height & $172.5 \pm 4.9$ & $172.6 \pm 4.9$ & -0.1 & $>0.05$ \\
\hline Weight & $58.8 \pm 6.8$ & $59.8 \pm 7.1$ & -0.9 & $>0.05$ \\
\hline Step test & $60.2 \pm 9.8$ & $65.3 \pm 21.4$ & -5.1 & $>0.05$ \\
\hline Vital capacity & $4186.1 \pm 449.1$ & $4214.4 \pm 478.0$ & -28.3 & $>0.05$ \\
\hline Standing long jump & $229.8 \pm 18.8$ & $28.9 \pm 19.0$ & $-9,0$ & $<0.01$ \\
\hline Gripping strength & $37.9 \pm 9.0$ & $37.5 \pm 8.8$ & 0.4 & $>0.05$ \\
\hline
\end{tabular}

The relationship between aerobics exercise and undergraduates’ physical quality is shown in Table 6 . 41 boys participated in aerobics event. In the table, the performance change of standing long jump is very significant $(p<0.01)$, and the remaining indexes do not change greatly $(p<0.05)$. Aerobics as an aerobic exercise is characterized by low intensity and large density. It plays an important role in improving cardio-pulmonary function and muscle endurance, and promoting coordinative operation of each organ. Students can make their skeleton strong, enhance muscle, and strengthen joint tenacity, elasticity and flexibility through aerobics. The improvement of standing long jump performance is closely related to aerobics exercise. Aerobics exercise is a long-term process. It is difficult to reflect the influence of aerobics on other indexes through one-semester teaching, so the remaining items have no significant change.

\section{Football}

Table 7. Undergraduates' physical quality test data in football event and data analysis

\begin{tabular}{|l|l|l|l|l|}
\hline Index & Before experiment & After experiment & Mean difference & $\mathrm{p}$ \\
\hline Height & $174.7 \pm 5.5$ & $174.9 \pm 5.4$ & -0.2 & $<0.01$ \\
\hline Weight & $63.4 \pm 9.0$ & $64.2 \pm 8.9$ & -0.8 & $>0.05$ \\
\hline Step test & $66.1 \pm 13.9$ & $66.9 \pm 11.9$ & -0.8 & $>0.05$ \\
\hline Vital capacity & $4155.5 \pm 685.7$ & $4400.2 \pm 662.2$ & -244.7 & $<0.01$ \\
\hline Standing long jump & $226.8 \pm 16.5$ & $237.3 \pm 16.8$ & -10.5 & $<0.01$ \\
\hline Gripping strength & $36.7 \pm 9.1$ & $38.3 \pm 9.9$ & -1.6 & $>0.05$ \\
\hline
\end{tabular}

The relationship between football exercise and undergraduates' physical quality is shown in Table 7 . 70 boys participated in football event test. It can be seen from the above table that, the weight, step test and gripping strength change little $(p>0.05)$, and the changes of the remaining three items are significant $(\mathrm{p}<0.01)$. Football is the optimal event to train legs. In the process of playing football, leg joint is exercised constantly, and muscle stretches continuously. Each function of the body also improves unconsciously. In particular, leg joint becomes very flexible and strong. Football is a comprehensive event with strong intensity and consumes physical power very much. Thus, vital capacity and standing long jump improve significantly, while step test and gripping strength do not improve significantly. Hence, students should enhance exercise in this aspect consciously.

\section{Suggestions}

Based on contrastive analysis of the above data and comparison of teaching results of experiment group and control group, we cab draw such conclusion that: physical education intervention teaching strategy contributes to enhancing students' physical quality and has high feasibility and good effect. Physical education intervention strategy greatly improves students' exercise enthusiasm and enhances their self-confidence. It's worth noting that teaching intervention strategy is not perfect. For different students, different methods should be applied to make each student benefit. In addition, students should participate in different forms of physical exercise if possible to further enhance physical quality. 


\section{References}

[1] Jin Li, Theoretical reflection of university physical education intervention strategy for physical education mode. Journal of Shangqiu Teachers College, 2003.19 (2):148.

[2] Xie Peina, Comparison and enlightenment of Sino-US university physical exercise and health course content. Journal of Physical Education, 2006.13 (3): 75-76.

[3] Guo Ping, Discussion on university physical exercise intervention strategy teaching mode and its improvement countermeasures. Journal of Mudanjiang College of Education, 2006, 96 (2):97.

[4] Zhou Yumin, After-class physical education learning and lifelong physical education. Chongqing: Southwest China Normal University, 2005. 